\title{
Cien Años de Soledad y el Concepto de la "Caída Afortunada"
}

Un aspecto muy importante del mito de Adán que con frecuencia aparece en la literatura norteamericana de finales del siglo xix y comienzos del xx es aquel que sostiene que la caída de Adán fue en verdad una "caída afortunada". Dicho tema, en la manera en que lo presenta R. W. B. Lewis en su concienzudo examen del Adán americano, podría fácilmente remontarse hasta el siglo Iv de la era cristiana. ${ }^{1}$ El himno litúrgico conocido como ExuLTET, de ascendencia medieval inconfundible, denominado también con la paradójica estrofa inicial de "O FELIX CULPA", sintetiza el concepto de la caída afortunada mediante el cual se postula que gracias al "desliz" de nuestros primeros padres, se hizo imperiosa la venida del Mesías y la redención consiguiente del género humano. ${ }^{2}$ Bajo esta interpretación se propone que el estado de inocencia

1 R. W. B. Lewis. The American Adam: Innocence, Tragedy, and Tradition in the Nineteentb Century (University of Chicago Press, 1968). El fundamento de nuestro estudio ha sido construido en torno a las ideas que Lewis discute en los siguientes capítulos: "The Fortunate Fall: The Elder James and Horace Bushnell" (3), pp. 54-74 que forma parte del primer capitulo titulado: T'be Danger of Innocence; "The Function of History: Banctoft and Parkman" (8), pp. 159. 173 y, "The Real Presence: Parker and Brownson" (9), pp. 174-193 que forman parte del tercer capítulo titulado: The Past and Perfect. [Todas las referencias a este libro provienen de esta edición. Por falta de una versión castellana del libro, he tenido que hacer la traducción de los textos usados transcribiendo el texto inglés original en las notas para que el lector verifique por su cuenta].

2 Lewis, haciendo eco a las investigaciones del profesor Lovejoy, sostiene que el himno ha sido usado durante muchos siglos por la Iglesia en las solemnes ceremonias de la bendición del Cirio Pascual del Sábado Santo. El título "oficial" del himno, tal como lo registran los manuales litúrgicos, es PRAECONIUM PASCHALE pero ha venido siendo familiarmente conocido con la primera palabra de la estrofa: "Exultet iam angelica turba caelorum". La letra latina del tragmento que usamos en este estudio ha sido tomada del Roman Missal (Benziger Brothers, New York, 1966, p. 346) y reza asi: "O felix culpa, quae talem ac tantum meruit habere Redemptorem! O vere beata nox, quae sola meruit scire tempus et horam in qua Christus ab inferis resurrexit! Haec nox est, de qua scriptum est: Et nox sicut dies illuminabitur: Et nox illuminatio mea in deliciis meis...".

El himno tiene también una larga tradición literaria que incluye el Libro XII de El Paráso Perdido de J. Milton - diálogo entre Adán y el Arcángel San Miguel- 
adínica anterior a la caída, no es más que una manera efectivísima de formular y representar la inmadurez, la niñez despreocupada y risueña que el hombre vivió en su estado paradisíaco. Sugiere también que dicha inmadurez se halla en la trágica inhabilidad de aquellos dos seres primigenios para reconocer la pre-medisida condena que pendía sobre sus vidas y que el acto de desobediencia (Arbol de la Ciencia y todas sus implicaciones) sólo se encargaría de hacer efectiva. Lewis define los térmi. nos de esia interpretación de Henry James, el mayor, con el siguiente razonamiento:

...para lograr entrar en las filas de la adultez, el hombre tuvo que cuer, tuvo que superar su niñez en un encuentro con el "Mal", tuvo que madurarse mediante la destrucción de su propio yo... (p. 55). El madurarse exigió una crisis del yo que en el Génesis se dramatiza con la caída de Adán: el fatal pero necesario desmorona. miento de la inocencia dentro del gran bloque del inconsciente en busca de la conciencia de su yo... (p. 58). - La caída de Adán y la caída de 'todo hijo de Adán'- [es] por excelencia afortu'. nada... 'La caída de Adán', tal como se le sucle llamar, no fue la desgracia tonta de perder el favor divino tal como vulgarmente se ha venido diciendo, sino la verdadera ascensión al nivel humano normal". (p. 60$)^{3}$

Sólo cuando Adán y con él la humanidad caen y se levantan hasta alcanzar el nivel humano, podrá entonces afirmarse que han sido lo sufi-

estudiado por Arthur O. Lovejoy: "Milton and the Paradox of the Fortunate Fall," de su libro Ersays in the History of Ideas (Baltimore, 1948), pp. 277-295. El rastreo del profesor Lovejoy lo llevó al estudio de los textos, sermones y distintas versiones e interpretaciones dadas o sostenidas por la Iglesia y los Padres de la Iglesia a lo largo de más de diez siglos de tradición a partir de Milton. Lovejoy destaca tres fuentes importantes en que se debió fundar Milton: Guillermo du Bartas y su poema La Seconde Semaine ("L'Imposture," Rouen, 1592) y dos coetáneos del poeta inglés: Giles Fletcher y su poema "Christ's Triumph over Death" (1610) y el tercer acto de L'Adamo (1613) de Andreini. Lovejoy discute las distintas razones para atribuir la paternidad del himno a tres santos: San Ambrosio, San Gregorio y el mismo San Agustin sin que se haya podido hallar una fuente original única.

3 La versión inglesa reza así: "...for in order to enter the ranks of manhood, the individual (...)had to fall, had to pass beyond childhood in an encounter witin "Evil," had to mature by virtue of the destruction of his own egotism... (p. 55). Growing up required the individuating crisis which in Genesis is dramatized as the fall of Adam: the fatal, necessary quickening within the unconscious chunk of innocence of the awareness of self... (p. 58)-of Adam's fall and the fall of "every son of Adam" - as essentially fortunate... "Adam's fall, as it is called, was not that stupid lapse from the divine favor which it has vulgarly been reputed to have been, but an actual rise to the normal human level." (Lewis, p. 60). 
cientemente afortunados en su tarea de buscar la resurrección y salvación finales a través de Cristo.

Sin embargo, para madurarse y poder levantarse hasta el nivel humano, se tiene que poseer conciencia de sí mismo primero que todo. De acuerdo con estas interpretaciones de James, el hombre lo logra por inter. medio de su caída en lo que Lewis considera: ". . los choques y sufrimien os indispensables que tienen la facultad de transformar, la experiencia y los errores - en suma, la experiencia- a través de la cual se habrá de llegar a la madurez y al logro de la identidad..." (p. 61)." La exper riencia resulta así el mayor aspecto determinante del proceso. El hombre debe someterse al dolor y al sufrimiento, tiene que aprender a distinguir y sentir una emoción profundamente antes de que pueda experimentar plena e intensamente la vida, si es que pretende alcanzar la noción de sí mismo (conciencia) que viene con el logro del nivel humano. El sentido primordial de la caída, así entendido, no radica en que se condenen las aspiraciones de Adán y sus descendientes al fracaso eventual, sino más bien a que, mediante el valor redentor de la experiencia en lo que ésta tiene de enseñanza y en oposición a aquella otra forma de experiencia dirigida hacia metas imposibles, a que se efectúe el acto de separación a partir de la inocencia que permitirá el levantamiento simultáneo del ser al nivel humano y al camino de su salvación final.

En este estudio los autores proponen que en Cien años de soledad el descubrimiento del amor y de la tragedia - incluyendo en esta última otros atributos de la condición adánica después de la caída tales como la soledad, el conocimiento de la caída eventual y la mortalidad que sim. boliza su humanidad - son los dos elementos constitutivos de la experiencia que, intensamente sentida, tiene la facultad de transformar "los choques y sufrimientos, la experiencia y los errores" (L. p. 61), a través de los cuales los Buendía alcanzan el conocimiento de sí mismos y su consiguiente salvación final.

En Cien años... el ascenso al nivel humano en la manera en que se acaba de exponer puede encontrarse como clímax o mediodía de la vida de cada Buendía. En las historias de ciertos personajes la naturaleza de la transformación aparece más explícitamente trazada que en las de otros. En el episodio final de la novela, la rendición del último Aureliano y la última Ursula podría servir de sumario de todo el libro porque ata en

4 La versión inglesa de Lewis dice así: ". . the necessary transforming shocks and sufferings, the experiments and errors -in short, the experience- through which maturity and identity may be arrived at. (p. 61). 
un solo cabo los temas principales de la obra. Comencemos por esta última pareja:

\section{El caso de Aureliano y de amaranta Ursula}

El amor desempeña un papel importantísimo en la experiencia que tiene el poder de transformar a Aureliano y a Amaranta Ursula porque, la vuelta intempestiva de Ursula de Europa trajo: ". . .un cambio radical en la vida de Aureliano..." (p. 324), ${ }^{5}$ quien ya no pudo retirarse y aislarse para desentrañar los textos de Melquíades, ahora que la presencia de Ursula le obliga a asirse a: ". . la voz que se le fugaba, la vida que se le iba, la memoria que se le convertía en un pólipo petrificado..." (p. 330). Los intentos por ahogar el desenfreno de su pasión con una prostituta resultan inútiles puesto que, cuando más experimenta el amor, tanto más intenso es el sufrimiento: ". . su pasión reprimida. . . que no había conseguido remediar con la sustitución, sino que le iba torciendo cada vez más las entrañas a medida que la experiencia ensanchaba el horizonte del amor..." (p. 326). Ya incapaz de aguantar el dolor: “...Aureliano se desbordó... abrió los pasadizos más recónditos de su corazón, y se sacó una tripa interminable y macerada, el terrible animal parasitario que había incubado en el martirio..." (p. 332). Pero cuando gana el amor de Amaranta Ursula, llega a experimentar el regocijo más intenso del amor. Fue ". . pasión insensata, desquiciante que hacía tem. blar de pavor en su tumba los huesos de Fernanda. Perdieron el sentido de la realidad, la noción del tiempo, el ritmo de los hábitos cotidianos... Se entregaron a la idolatría de sus cuerpos, al descubrir que los tedios del amor tenían posibilidades inexploradas, mucho más ricas que las del deseo..." (pp. 340-41).

La experiencia del amor ha logrado transformar tanto a Aureliano como a Amaranta Utsula, a quienes los convicrte en seres únicos e incon. fundibles: ". . los únicos seres felices, y. los más felices sobre la tierra. . ." (p. 340). Esta metamorfosis es un paso inicial en la trayectoria ascen. dente en busca de la condición humana. Debe notarse en este episodio la forma explícita en que García Márquez enfatiza el invalorable papel de transformador que conlleva el amor. Valiéndose de Pilar Terneta sugiere que dicho amor siempre ha desempeñado tal función. Lo cual explica por qué Amaranta Ursula es origen de pena para Aureliano, y por qué

5 Gabriel Garcia Márquez, Cien años de soleddd. (Editorial Suramericana, $1967)$, p. 324. [Todas las referencias a este libro provienen de esta edición.] 
en la mente de Pilar Ternera, el reconocimiento del dolor es instantáneo. El autor anota sumariamente que "... sin que él le hubiera revelado que estaba llorando de amor, ella reconoció de inmediato el llanto más anti. guo de la historia del hombre... (p. 334). Afirma así que la intensidad de la experiencia del amor es tan antigua como la historia del hombre en el planeta. Más aún, es este mismo amor el único paliativo que hace llevadera la soledad del universo vacío. Aureliano y su amante "...se iban convirtiendo en un ser único, se integraban cada vez más en la soledad... (p. 345), o también que "... ambos quedaron flotando en un universo vacío, donde la única realidad cotidiana y eterna era el amor..." (p. 342).

Tomada por separado, la intensidad de la experiencia del amor no es suficiente para que se alcance la conciencia del yo que hace posible el ascenso a la condición humana. También se necesita la intervención de la tragedia. De suerte que por la única vía del amor Aureliano y Amaranta Ursula no habian madurado definitivamente. Y puesto que aún desconocen la tragedia, se aferran a la idea ingenua de que la Raza de los Buendía todavía tenía mucho camino que recorrer, creyendo para sí que el hijo a punto de nacer y testimonio del amor y la esperanza, es. taba "...predispuesto para empezar la estirpe otra vez por el principio y purificarla de sus vicios perniciosos y su vocación solitaria" (p. 346). Estaban así en estado de inocencia.

La muerte de Amaranta Ursula, inmediatamente después del parto, y la muerte trágica del niño devorado por las hormigas a pocas horas de nacido, introdujo en la vida de Aureliano una nueva dimensión del dolor: la que trae consigo la tragedia. El autor atestigua esta nueva compren. sión diciendo: "Lloró... consciente de que estaba pagando los llantos atrasados de una muerte que no quiso llorar a tiempo [la de su amante unas horas antes] para no romper los hechizos del amor" (p. 348). Encontrándose ahora en el mismo lugar en que sus antepasados vivieran sus propias tragedias, se nos dice que: "...tuvo conciencia de que era incapaz de resistir sobre su alma el peso abrumador de tanto pasado" (p. 349). Aquí mismo sufre Aureliano por primera vez las punzadas de la nostalgia que provienen del pleno conocimiento de que la dicha del pasado se ha perdido irrevocablemente: ... herido por las lanzas mortales de las nostalgias propias y ajenas" (p. 349). Junto al entendi. miento de la tragedia en que vive este momento crucial, Aureliano logra una madurez mayor. El autor la visualiza mediante la añoranza de los amigos que otrora abandonara: "Aureliano no comprendió hasta entonces cuánto quería a sus amigos, cuánta falta le hacían, y cuánto hubiera 
dado por estar con ellos en aquel momento" (p. 347). García Márquez sintetiza el ámbito de esta súbita comprensión valiéndose de una bella imagen poética alusiva a la fugacidad de la felicidad humana en contraste con la permanencia de la naturaleza: "Herido por las lanzas mortales de las nostalgias propias y ajenas, admiró la impavidez de la telaraña en los rosales muertos, la perseverancia de la cizaña, la paciencia del aire en el radiante amanecer de febrero" (p. 349).

El último Aureliano es también el primer Buendía que logra un co. nocimiento razonable y abarcador sobre la naturaleza inherentemente trágica de la circunstancia en que vive. Leyendo los textos de Melquíades en la soledad de "la última madrugada de Macondo", Aureliano se enfrenta al descubrimiento de que el linaje de los Buendía había sido condenado a la destrucción desde todo tiempo. Su última comprensión fue la de que el hombre es incapaz de utilizar el conocimiento que tenga de sí mismo y de su circunstancia, noción que se adquiere con la madurez, puesto que en su caso, después de lograrla, es sentenciado a morir. Adquirir tal verdad es perder la inocencia y ponerse en camino de la condición humana. Pero la ruina de la humanidad de Adán es la mortalidad y por eso mismo el hombre no puede tener "segunda oportunidad" sobre la tierra. En suma, Aureliano descubre que la ciencia de los pergaminos de Melquíades es intransferible e irrepetible: "...todo lo escrito en ellos era irrepetible desde siempre y para siempre, porque las estirpes condenadas a cien años de soledad no tenían una segunda oportunidad sobre la tierra" (p. 351). Y aquí, en uno de los pasajes más sobresalientes de la novela, García Márquez, con redoblada astucia narrativa, aprisiona y transcribe este "actual rise to a normal human level... the fatal, necessary quickening within the unconscious chunk of innocence of the awareness of self... (Lewis, pp. 58-64), atando en un solo nudo la cuerda de la novela hasta aquí leída con la del manuscrito de Melquíades ahora descifrado: "Aureliano saltó once páginas para no perder el tiempo en hechos demasiados conocidos, y empezó a descifrar el instante que estaba viviendo, descifrándolo a medida que lo vivía, profetizándose a sí mismo en el acto de descifrar la última página de los pergaminos, como si se estuviera viendo en un espejo hablado..." (p. 350). El per. gamino se convierte en el "espejo que habla" en un sentido metafórico, espejo en el que, al mirarse, descubre su propio yo, el reflejo de su yo. Aureliano ha caído y perdido su inocencia pero a la vez ha descubierto su humanidad.

Con anterioridad a la tragedia, Aureliano y Amaranta Ursula se habían dado cuenta de que la experiencia, en su caso las obsesiones 
dominzontes de la familia Buendía, los aproximaba, por un camino nada convencional, a la inmortalidad: ". . y entonces aprendieron que las obsesiones dominantes prevalecen contra la muerte" (p. 346). Lo cual explica por qué el narrador espera que el lector no se sorprenda cuando anota que la pareja podía incluso oír a Ursula "...peleando con las leyes de la creación para conservar la estirpe, y a José Arcadio Buendía buscando la verdad quimérica de los grandes inventos, y a Fernanda rezando, y al coronel Aureliano Buendía embruteciéndose con engaños de guerra y pescaditos de oro, y a Aureliano Segundo agonizando de soledad en el aturdimiento de las parrandas" (p. 346). Explica también por qué los inunda esa extraña alegría cómplice que resulta del enten. dimiento de que ellos, último rezago de la familia: ". . seguirían amándose con sus naturalezas de aparecidos, mucho después de que otras especies de animales futuros les arrebataran a los insectos el paraíso de miseria que los insectos estaban acabando de arrebatarles a los hom. bres" (p. 346).

\section{El caso de Fernanda del Carpio}

Fernanda también sufre una crisis íntima y peculiar hacia el final de sus dias, crisis que le permite ascender has'a el nivel humano y que le garantiza la salvación final. El episodio en que se recuenta reviste importancia especial porque en él, el narrador enlaza explícitamente el concepto del ascenso a la condición humana junto con el de la experiencia intensa y completa que trae la tragedia.

$Y$ tal como le aconteciera al último Aureliano, la nostalgia constituye para Fernanda la experiencia, sufrida iniensamente, que posee los mismos poderes transformadores de la tragedia. La "nostalgia de los sue. ños perdidos" (p. 305), el sentimiento de que la felicidad de su niñez - -sentimiento encarnado en el sueño.ilusión de "llegar a ser reina", estaba irremediablemente abocado al fracaso-, se hacen presa de su espíritu acongojado al final de su exsitencia. $Y$ a causa de esta nostalgia, por primera vez en su vida Fernanda experimenta una sensación de tristeza:

...su corazón de ceniza apelmazada, que había resistido sin quebrantos a los golpes más certeros de la realidad cotidiana, se desmoronó a los primeros embates de la nostalgia. La necesidad de sentirse triste se le iba convirtiendo en un vicio a medida que la devastaban los años... (p. 308). 
El narrador tiene sumo cuidado en dejar impreso en el lector el grueso calibre de la soledad del personaje. Añora así con tanta intensidad los días dorados de la juventud que muchísimos años después puede todavía ré-experimentar los acontecimientos más triviales con términos eminentemente sensoriales:

. . los ojos se le llenaron de lágrimas, porque en aquel instante volvió a percibir el olor de betún de las botas del militar que fue a buscarla a su casa para hacetla reina ... y sólo entonces descubrió cuánta falta bacian las ráfagas de orégano en el corredor, y el valor de los rosales al atardecer, y hasta la naturaleza bestial de los advenedizos... (p. 308).

El descubrimiento que Fernanda hace de los dolores de la nostalgia es en verdad el descubrimiento de su yo intransferible. $Y$ en la misma forma en que le aconteciera al último Buendía, este enfrentamiento ante sí misma viene otra vez transmitido a través de la imagen del espejo, tal como sutilmente lo sugiere esta cita:

Cualquiera que la hubiera visto frente al espejo, extasiada en sus propios ademanes monárquicos, habría podido pensar que estaba loca. Pero no lo estaba. Simplemente, babía convertido los atuendos reales en una máquina de recordatr. (p. 308).

La experiencia de la tristeza y de la nosialgia unidas hacen que Fernanda suba al nivel humano en medio de su soledad adánica. Después de decirnos que el deseo de sentirse triste tiene características de "vicio", el autor anota casi al descuido que el personaje: "se humanizó en la soledad" (p. 308), con lo cual pone una vez más en evidencia que mediante estas crisis individualizadoras los Buendía ascienden al nivel hu. mano antes de morir.

\section{El caso del coronel Aureliano Buendía}

Tal como Fernanda, el coronel se levanta hasta alcanzar el nivel humano un poco antes de su muerte, unos cuantos minutos antes, para ser exactos. $Y$ una vez más, el autor simboliza la ascensión a través de la imagen del protagonista en el acto de auto-descubrirse, de hallar su yo en el espejo. Este episodio, que comienza en la página 226 con la frase: 
"No se le volvió a ver una reacción humana", y que va hasta el final del capítulo en la página 229, es definitivamente único, distinto y peculiar, comparado con el resto de la novela. Aquí, el autor altera, con deliberado propósito, tanto el estilo habitual como la naturaleza del asunto que pretende narrar. La función de esta alteración sirve el propósito nada obvio de poner en evidencia la intensidad de la experiencia transformadora del coronel al final de su vida y por medio de la cual no fuera una excepción a la familia.

Tanto en el episodio en que se recuentan los pormenores de'su muerte, como en los sucesos que la preceden, claramente se destaca la incapacidad innata del coronel para sentir o experimentar los efectos del amor o de la tragedia. Dicha incapacidad ha sido causante del: "...frío interior que le rayaba los huesos y lo mortificaba inclusive a pleno sol" (p. 146), o del "...frío que había de acompañarlo hasta la muerte." (p. 147).

El coronel hasta ahora no ha sentido el amor ni siquiera por Ursula, su paciente e incansable madre, de quien el autor en este contex'o dice que llevaba: ". . los arañazos, los verdugones, las mataduras, las úlceras y cicatrices que había dejado en ella más de medio siglo de vida coti. diana" (p. 152). Su vida sentimental es, pues, un desierto y un vacio en los que no habrá de encontrar nada a pesar de la búsqueda:

...y comprobó que esos estragos no suscitaban en él ni siquiera un sentimiento de piedad. Hizo entonces un uiltimo esfuerzo para buscar en su corazón el sitio donde se le babían podrido los afectos, y 20 pudo encontrarlo... (p. 152).

Por otra parte, el coronel tampoco podía sentir los efectos de la tragedia porque hasta ahora ha sido capaz de evitar el sufrimiento y la nostalgia que trae el recuerdo de la felicidad ya ida: "... no le dolieron... nin. guna de las trampas insidiosas que le tendía la nostalgia" (p. 151) y porque había aprendido a evitar cualquier sentimiento de emoción como arma de defensa: ". . había aprendido a pensar en frío, para que los recuerdos ineludibles no le lastimaran ningún sentimiento" (p. 228).

La alteración deliberada de la prosa con que se narra la muerte del coronel consiste en el empleo de una técnica retardativa con la que se consigue desacelerar el ritmo de la marcha o la velocidad que la narrativa ha tenido hasta ahora. Así que en vez de saltar ágilmente de un acontecimiento a otro sin revelar detalles sobre las circunstancias, en vez de pasar por alto largo períodos indefinidos con un párrafo, e incluso, con 
una sola frase, en la forma en que lo hace con frecuencia a lo largo de todo el libro, el autor decide detenerse a describir ceremoniosamente lo que aparentemente: "... había sido para el coronel Aureliano Buendía una jornada igual a todas las de sus últimos años" (p. 226), teniendo cuidado en agregar, casi al descuido, que éste fue también el último además del único día en que al personaje se le había notado: ". . .una reacción humana" (p. 226).

$\mathrm{El}$ autor se vale de varias fórmulas para retardar el ritmo: en primer lugar, no hay actividad, por nimia y trival que parezca, que no esté descrita en detalle y con minuciosidad casi desesperante, como puede ob. servarse en estos tres momentos:

ent el acto de vestirse:

...Se puso los pantalones estrechos, pero no se cerró las presillas, ni se puso en el cuello de la camisa el botón de oro que usaba siempre, porque tenía el propósito de darse un baño... (p. 226).

en el acto de salir al patio:

...Luego se puso la manta en la cabeza, como un capirote, se peinó con los dedos el bigo chorreado, y fue a orinar en el patio... (p. 226).

en el acto de comer:

...no levantó la vista del primer pescadito del día, porque estaba engastando los rubíes de los ojos. Sólo cuando lo terminó y lo puso con los otros en el tarro, empezó a tomar la sopa. Luego se comió, muy despacio, el pedazo de carne guisada con cebolla, el arroz blanco y las tajadas de plátano fritas, todo junto en el mismo plato... (p. 227).

En segundo lugar, las referencias al estado del tiempo atmosférico, que tienen poca o ninguna relación directa con los hechos descritos en el episodio, aparecen con frecuencia casi excesiva y ciertamente redundante en el transcurso de sólo tres páginas:

...A las cinco de la madrugada (p. 226)

...La llovizna persistía desde el sábado (p. 226)

...Faltaba tanto para que saliera el sol (p. 226) 
.. sino por la neblina opresiva de octubre (p. 226)

.. Había escampado, pero aún no salía el sol (p. 228)

... sin darse cuenta que a las diez arreció la lluvia (p. 227)

...viendo que el aire empezaba a secar (p. 228)

...el sol salió con tanta fuerza (p. 228)

...El aire lavado por la llovizna de tres días (p. 228)

...decidió que era un buen momento para bañarse (p. 228)

...y no quedó sino el luminoso espacio de la calle (p. 229), etc.

Es curioso notar que aqui García Márquez está volviendo al modelo que siguiera en la configuración de aquel otro coronel de su obra anterior: El coronel no tiene quien le escriba. Aquí como allí hay un intento expreso de enfatizar la naturaleza del aburrimiento y la desesperanza, con la parsimonia como técnica de detener el flujo del tiempo cuando la vida parece inútil y carente de metas reales. Esta lentitud en el ritmo de la prosa contribuye a resaltar la lentitud mental y física que caracteriza la conducta del coronel a punto de morir. Por ello el personaje, desganado y resentido con su vida, apenas tiene conciencia de sus actos hasta el punto que más bien éstos parecen instintivos e infra-racionales. Dice así que el coronel pasaba muchas horas: "... sin pensar en nada" y que en las contadísimas ocasiones en que lograba pensar en algo, el proceso es tan lento como lo es la mecánica de sus movimientos "ins'intivos", para ir a comer o a cumplir sus necesidades fisiológicas: "... entonces cayó en la cuenta de que tenía deseos de orinar" (p. 228). Acercándolo así al nivel animal por la naturaleza de sus hábitos y reacciones, el autor anota:

...El coronel Aureliano Buendía emitió un erupto sonoro que le devolvió al paladar la acidez de la sopa, y que fue como una orden del organismo para que se echara la manta en los hombros y fuera al excusado. (p. 228).

Al final, sin embargo, el coronel experimenta las congojas ineludibles de la tragedia, es decir, la nostalgia que tanto tiempo ha logrado evitar. De pronto se encuentra añorando aquella tarde lejana y borrosa de su niñez en que por primera y última vez cree haber sido feliz en su vida. Fue la época en que el circo vino a Macondo. El coronel así también: ". . pisó conscientemente una trampa de la nostalgia, y revivió la prodigiosa tarde de gitanos en que su padre lo llevó a conocer el hielo" (p. 229). El secreto estilístico del cambio súbito empleado aquí radica en que, en vez de "decirle" al lector que el coronel también tuvo que 
sufrir los dolores de la nostalgia, el autor prefiere volcar la escena ante los ojos del lector. Y lo hace en forma muy efectiva al contrastar la condición emocional del personaje antes de que viera el circo, con la condición emocional del mismo despuiés de haberlo visto, bajo el denominador común de la lentidald que ya hemos expuesto. La intensidad del sufrimiento que debe tener la experiencia transformadora se refleja en este caso en la manera repetitiva y obsesionante con que se insiste en la palabra "vio" a fin de canalizar e individualizar el proceso visual en que el circo vuelve a las pupilas del niño de antaño:

...En vez de ir al castaño, el coronel Aureliano Buendía fue tam. bién a la puerta de la calle y se mezcló con los curiosos que contemplaban el desfile. Vio una mujer vestida de oro en el cogote de un elefante. Vio un dromedario triste. Vio un oso vestido de holandesa que marcaba el compás de la música con un cucharón y una cacerola. Vio los payasos haciendo maromas en la cola del desfile, y le vio otra vez la cara a su soledad miserable cuando todo acabó de pasar, y no quedó sino el luminoso espacio en la calle, y el aire lleno de hormigas voladoras, y unos cuantos curiosos asomados al precipio de la incertidumbre. (p. 229).

La aparición de cada uno de los payasos del circo fue para el coronel motivo de dolor y pena porque reconoció en ellos el origen de su propia nostalgia. El personaje se da cuenta de que el desfile ya ha pasado ante sus ojos de la misma forma en que su alegría habia ya pasado y muerto tantos años atrás. En este momento crucial el autor anota que en el vacío que deja el "luminoso espacio de la calle", el personaje logra al fin verse a sí mismo en el espejo de su mente, mediante un acto de reconocimiento descrito aqui como: "...la cara de su soledad miserable".

Además de presentar la soledad en su ambiente y circunstancia temporal que ya hemos discutido, García Márquez realza con una bella imagen poética la intensidad del sufrimiento remisor del coronel, al describir su muerte, cuyo causante ha sido, como en los otros Buendía, el dolor, la congoja de verse ante la coartada de su propio destino:

...Entonces fue al castaño, pensando en el circo, y mientras orinaba trató de seguir pensando en el circo, pero ya no encontró el recuerdo. Metió la cabeza entre los hombros, como un pollito, y se quedó inmóvil con la frente apoyada en el tronco del castaño... (p. 229). 


\section{El caso de Amaranta Buendía}

Al final de sus días Amaranta Buendía también sufre la crisis individualizadora por la que llega al nivel humano. Durante su larga vida, Amaranta había amado y sufrido intensamente la tragedia. Y sin embargo, la experiencia que le dieran estas emociones con poderes transfigurativos, fue muy limitada hasta el día de su crisis final. Con el descubrimiento de su soledad y sabiendo que sólo le quedan unos pocos dias de vida, de pronto amaranta siente el efecto combinado del amor y de la tragedia. Y una vez más, la imagen del espejo sirve de símbolo del confrontamiento con su propia conciencia solitaria. Ursula misma comprendió al final de su carrera que a pesar de la aparente impenetrabilidad del corazón de su hija, Amarantá era: ". . en el último examen... la mujer más ticrna que había existido jamás" (p. 214) y que la tortura a que había sometido a sus pretendientes había sido determinada por: ". . una lucha a muerte entre un amor sin medidas y una cobardía invencible, y había triunfado finalmente el miedo irracional que Amaranta le tuvo siempre a su propio y atormentado corazón" (p. 214). Claramente se ve que el personaje había sufrido siempre a causa de su infatigable corazón.

La experiencia de la tragedia se acentuó en su ancianidad y como todo Buendía Amaranta también sucumbió ante la nostalgia. Añora así aquellos días de su ilusionada juventud, aquellas tardes y aquellas veladas dedicadas a las clases de baile con Pietro Crespi:

. . Había llegado a la vejez con todas sus nostalgias vivis. Cuando escuchaba los valses de Pietro Crespi, sentía los mismos deseos de llorar que turo en la adolescencia, como si el tiempo y los escar. mientos no sirvieran de nada... (p. 236).

Pero aún así, la experiencia de esta angustia no fue suficiente para redimirla de la inocencia. Le hacía falta aquella faceta que invariablemente va asociada con el verdadero mor: la compasión por el sufrimiento de los demás. Amaranta habia llevado sobre sí la pesada e inútil carga de toda una vida de odio hacia Rebeca quien, a partir de la misteriosa muerte de su esposo José Arcadio, decidió retirarse totalmente del mundo. El odio de Amaranta llega al extremo de suplicarle a Dios que: ". . no le mandara el castigo de morir antes que Rebeca. Cada vez que pasaba por su casa y advertía los progresos de la destrucción se complacía con la 
idea de que Dios la estaba oyendo" (p. 237), e incluso concibió el plan malévolo de embellecer el cadáver de Rebeca, una vez que su hermanas. tra muriera, para sentir el placer sumo de ponerlo a la disposición de los gusanos: "...Elaboró el plan con tanto odio que la estremeció la idea de que lo habría hecho de igual modo si hubiera sido con amor..." (p. 237) en que se ve que Amaranta todavía no se había elevado al nivel humano.

El presentimiento infalible de que moriría muy pronto produjo la crisis individualizadora al imaginarse la muerte en la forma de: ". . una mujer vestida de azul con el cabello largo, de aspecto un poco anticuado" (p. 238) que le o.orgaba a Amaranta: "...el privilegio de anunciarse con varios años de anticipación" (p. 238). Indudablemente que este preaviso fue un privilegio que le permitiría volverse sobre sí para verse desde una perspectiva que no había conocido antes. $Y$ al darse cuenta que la muerte la iría a privar del placer que le inspirara el odio por Rebeca, siente una gran frustración e impotencia ante el destino que todo tergiversa:

...A medida que se aproximaba el término ineludible, iba comprendiendo que sólo un milagro le permitiría prolongar el trabajo más allá de la muerte de Rebeca, pero la misma concentración le prolongó la calma que le hacía falta para aceptar la idea de una frustración... (p. 238).

Aceptando su frustración frente al gran objetivo de su vida, Amaranta logró la calma necesaria para pensar en sí misma. Y fue así como descubrió su propia soledad. A través de lo que el autor llama "com. prensión sin medidas" (p. 238), hallose de repente atribulada por las penas ajenas. Comprendiendo el mal y el error de su pasión mal encami. nada, sintió deseos de: ". . rescatar a Rebeca de su salsa de miseria, no por odio ni por amor, sino por la comprensión sin medidas de la soledad" (p. 238).

Su comprensión se extiende a otros miembros de la familia; hacia su hermano, el coronel Aureliano perdido en el: ". . círculo vicioso de los pescaditos de oro" (p. 238). Esta forma de revelación postrera lleva poderes transformadores puesto que gradualmente: "...el mundo se re. dujo a la superficie de su piel, y el interior quedó a salvo de toda amar. gura" (p. 238).

Pero en la medida en que Amaranta se abría al mundo de la com. pasión, en esa misma medida sufría la magnitud de la tragedia de su 
vida. $\mathrm{Y}$ es que entiende perfectamente bien que la compasión le había sido concedida demasiado tarde puesto que estaba condenada a morir antes de que pudiera emplearla en la edificación de una existencia más feliz para sí y para los demás:

...Le dolió no haber tenido aquella revelación muchos años antes, cuando aún fuera posible purificar los recuerdos y reconstruir el universo bajo una luz nueva, y evocar sin estremecerse el olor de espliego de Pietro Crespi al atardecer, y rescatar a Rebeca de su salsa de miseria... (p. 238).

$Y$ tal como lo discutiéramos al hablar del último Buendia, lo que Amaranta está reflexionando es un tema que se hace evidente al final de la novela, el de que la tragedia real del hombre es la de su mortalidad puesto que no hay "segunda oportunidad sobre la tierra" (p. 351) para construir una vida mejor.

García Márquez utiliza aquí la imagen del espejo que refleja la verdadera imagen y conciencia del personaje. Amaranta entonces: ". .le pidió a Ursula un espejo y por primera vez en más de cuarenta años vio su rostro devastado por la edad y el martirio, y se sorprendió de cuánto se parecía a la imagen mental que tenía de sí misma. . (pp. 240 41). Así que humana y mortal, Amaranta muere unos minutos más tarde.

\section{El caso de Arcadio Buendía}

Arcadio se quedó en Macondo a la salida del coronel Aureliano en una de sus campañas revolucionarias. Su misión consistía en administrar el pueblo como sustituto directo del coronel. Muy pronto, sin embargo, Arcadio reveló su talento para la crueldad y el despotismo. Fusiló gente inocente, ayudó con su influencia a que se usurparan las tierras de los vecinos con falsos títulos de propiedad, reclamó impuestos ilegalmente e incluso llegó al extremo de imponer castigos vergonzosos de flagela. ción al mismo suegro del coronel Aureliano convirtiéndose en: "...el más cruel de los gobernantes que hubo en Macondo" (p. 95). No obstante, en las dos últimas horas de su vida, comprendiendo que su fusilamiento era inminente, también sufrió una transformación profunda al experimentar plenamente el sabor del amor y la tragedia, dimensiones hasta ahora ausentes de su conciencia. De suerte que como los demás de su linaje, Arcadio también gana el nivel humano antes de morir. 
En forma similar a la que usara el autor para evidenciar la tragedia del coronel Aureliano, aquí también se vale del estilo y de la acción. $\mathrm{L}_{a}$ intensidad del descubrimiento del amor en Arcadio se refleja en la reticente y acompasada repetición de la palabra "pensaba" en el pasaje en que se puntualiza su monólogo interior mientras un tribunal militar com. pleta y oficializa su condena al paredón de fusilamientos:

...Impasible, sin preocuparse siquiera por demostrar su reciente valor, escuchó los interminables cargos de la acusación. Pensaba en Ursula, que a esa hora debía estar bajo el castaño tomando el café con José Arcadio Buendía. Pensaba en su hija de ocho meses, que aún no tenía nombre, y en el que iba a nacer en agosto. Pensaba en Santa Sofía de la Piedad, a quien la noche anterior dejó salando un venado para el almuerzo del sábado, y añoró su cabello chorreado sobre los hombros y sus pestañas que parecían artificiales. Pensaba en su gente sin sentimentalismos, en un severo ajuste de cuentas con la vida, empezando a comprender cuánto quería en realidad a las personas que más había odiado... (pp. 106-7).

De manera que cada acto del recuerdo sobre un miembro de la familia, se convertía en una nueva luz sobre la base amorosa en que se habían levantado tantos resentimientos cuyos efectos ya nunca podría reparar a pesar del hallazgo.

$\mathrm{La}$ intensidad de dicho hallazgo también viene atestiguada con la acción porque para Arcadio, como todo Buendía, la nostalgia es la ma. nifestación más evidente de la transformación que se opera en ellos:

...En realidad no le importaba la muerte sino la vida, y por eso la sensación que experimentó cuando pronunciaron la sentencia no fue una sensación de miedo sino de nostalgia... (p. 107).

Tanta fue la tristeza que le causó la noticia de su muerie como privación de una segunda oportunidad, que Arcadio alcanzó a re-vivir una vez más los episodios dominantes de su corta existencia atribulada por la violencia. $\mathrm{La}$ añoranza lo llevó a reexperimentar, incluso en sus detalles más nimios, escenas de gran fondo sensorid:

...En ese instante le apuntaton las bocas abumadis de los fusiles, y oyó letra por letra las encíclicas cantadas de Melquíades, y sintió los pasos perdidos de Santa Sofía de la Piedad, virgen, en el salón 
de clases, y experimentó en la nariz la misma dureza de bielo que le había llamado la atención en las fosas nasales del cadíver de Remedios... (p. 108).

Aunque la confrontación explícita con el espejo que hemos visto en los otros personajes no existe aquí, quizá no sea del todo disparatado decir que el mismo enfrentamiento parece implícito aquí en el "acto de oír" que ejecuta Arcadio de las "encíclicas cantadas de Melquíades" (p. 108). Porque, como ya lo hemos afirmado, al final de Cien años... el pergamino de Melquíades está visto como un "espejo hablado". (p. 350) en el que mitándose, el último Buendía encontró su propio yo, Es entonces lógico extender la función metafórica del auto-descubrimiento para explicar la autenticidad de la tragedia que realmente sufre Arcadio antes de ser fusilado.

\section{El caso de Aureliano Segundo y Petra Cotes}

La compleja e ilícita relación entre estos dos seres a lo largo de tantos años se denomina "complicidad estéril" (p. 288), pues el tiempo se les iba en: ".. las parrandas desatinadas, la riqueza aparatosa y la fornica: ción sin frenos" (p. 288).

Pero con aquel increíble diluvio que duró cuatro años, once meses y dos días, se operó en ellos una transformación radical al cabo de la cual indudablemente ascendieron al nivel humano. Para comenzar, dicha metamotfosis se inicia con la súbita suspensión de la que hasta entonces fuera milagrosa reproducción del ganado, que los llevara hasta los bordes mismos de la abundancia como estorbo. Y se asienta en ellos el espectro de la pobreza gradual e irreversible. Con la aparición de ésta, sin embargo, experimentan por primera vez los efectos del verdadero amor y de la verdadera tragedia. Porque en la manera en que lo intuye Petra, parece que: ". .la pobreza era una servidumbre del amor" (p. 288); y mientras Aureliano Segundo se afanaba en hallar la causa de la repen. tina esterilidad de sus animales, se nos dice que: ".. escarbó tan profundamente en los sentimientos de ella, que buscando el interés encontró el amor, porque tratando de que ella lo quisiera terminó por quererla..." (p. 288). De Petra, por su parte, se dice que: ". . lo iba queriendo más a medida que sentía aumentar su catiño" (p. 288).

$Y$ es que no solamente llegaron a sentirse: ". . .locamente enamorados al cabo de tantos años de complicidad estéril" (p. 288), sino que tam- 
bién, por primera vez, sintieron compasión desinteresada por las penas de los demás. Con frecuencia aguantaron las premuras del hambre, ellos que años atrás hubieran llegado al exceso de empapelar toda la casa con billetes para divertirse con el espectáculo, a fin de que Fernanda pudiera disfrutar de un poco más de dinero para suplir sus necesidades. El narrador explica que: "...no lo hicieron nunca por remordimiento ni por caridad, sino porque su bienestar les importaba más que el de ellos mis. mos" (p. 287).

Pero Aureliano Segundo y su compañera Petra experimentaron los salobres efectos de la tragedia -en forma de nostalgia- en forma simultánea y similar en que sintieron los efectos consoladores del amor acrecentado por él: "... sentimiento de solidaridad que en ambos había despertado la miseria" (p. 286). Se dieron cuenta de que el descubrimiento del amor les había llegado sencillamente demasiado tarde y que, deplorándolo o no, ya habían perdido irrevocablemente muchos años de vida y auténtica felicidad en eso que con anterioridad se calificara de "complicidad estéril". Disfrazando los verdaderos sentimientos de frustración ante el absurdo, se dedican a reparar lo irreparable con rifas y loterias cada vez más frecuentes (idea de lo absurdo a través de lo cíclico o circular), en forma semejante a la del coronel Aureliano frente a sus "pescaditos de oro". En la visión espectral que tuviera el último Buendía, Aureliano Segundo habrá de ser caracterizado con una frase que resume el sentido de su tragedia íntima diciendo que estaba: ". . .ago. nizando de soledad en el aturdimiento de las parrandas" (p. 346). Tal sentido de fatalidad ante los enigmas del presente, viene acrecentado con la evocación en términos de tiempo perdido:

...Ambos evocaban entonces como un estorbo las parrandas desati. nadas, la riqueza aparatosa y la fornicación sin frenos, y se lamentaban de cuánta vida les babia costado encontrar el paraiso de la soledad compartida... (p. 288)

6 La idea paradójica del "paraíso de la soledad compartida" que expresa la profundidad de la soledad frente a la desolación espacial que delimita el universo vital de esta pareja, parece ser una paráfrasis de lo que dijera al respecto el poeta español Ramón de Campoamor en un poemita titulado "Hastío" de sus Doloras (Dolora No. 17) que reza así: / "Sin el amor que encanta, / La soledad de un ermitaño espanta. / iPero es más espantosa todavía / la soledad de dos en compañía! / ". Clásicos Castellanos, no. 40, p. 129. [Hablando sobre la soledad como circunstancia vital, García Márquez hizo alusión al poemita de Campoamor en una charla que sostuve con el autor en agosto de 1970 en Barcelona con una frase que pronunció como si fuera una fórmula o receta y que transcribo aquí: "La soledad es todo lo contrario de la solidaridad. En la soledad - dice- no puede haber amor". He subrayado la palabra amor porque García Márquez la repitió tres veces con gran énfasis.] 
Puede entonces así verse cómo la tragedia y el amor como experien. cias vitales han sido evidencias de la mortalidad como condición que permite que cada Buendía suba y gane su nivel humano antes de morir.

$\mathrm{Y}$ una vez más, la imagen del espejo como reflejo e identidad del yo consciente que saliera de la inocencia adánica, aparece aquí vertida en la personificación de la pobreza como causante de los desvelos de la pareja y como evidencia del proceso de des-posesión de todos aquellos objetos que antaño simbolizaran la abundancia y que ahora resaltan por su ausencia. Conviene observar aquí el valor estilístico de los prefijos: re y de, des y mal.

...Para Petra Cotes, sin embargo, nunca fue mejor hombre que entonces, tal vez porque confundía con el amor la compasión que él le inspiraba, y el sentimiento de solidaridad que en ambos habia desperiado la miseria. La cama desmantelada dejó de ser lugar de desafueros y se convirtió en refugio de confidencias. Liberados de los espejos repetidores que habían remariado para comprar animales de rifa, y de los damascos y terciopelos concupiscentes que se había comido la mula, se quedaban despiertos hasta muy tarde con la inocencia de dos abuelos desvelados, aprovechando para sacar cuen. tas y trasponer centavos el tiempo que an'es malgastaban en mal. gastarse... (pp. 280.7).

\section{El caso de José Arcadio Buendía, "el Fundador"}

José Arcadio llegó también al descubrimiento de la conciencia de su yo a través del auto-descubrimiento de su tragedia y de su amor. Muchos años antes, José Arcadio había dado muerte a otro ser humano, Pru. dencio Aguilar, a raíz de un insulto interpretado como cuestión de honor. Pero de inmediato, José Arcadio sufrió tanto: "un malestar de concien. cia" (p. 26), como la inquietante presencia del fantasma de su víctima. Intentó entonces tranquilizar su conciencia y dar descanso al fantasma de su amigo, marchándose de Riohacha para siempre. Y una vez establecido en Macondo, el incidente fue gradualmente borrándose de su memoria, con lo cual parece que hubiera triunfado en el intento de esca. par de la pesadilla de su pasado. Pero el fantasma, para quien: ". . era tan intensa la añoranza de los vivos, tan apremiante la necesidad de compañía, tan aterradora la proximidad de la otra muerte que existía dentro de la muerte..." (p. 73), llegó a "querer al peor de sus enemi- 
gos" (p. 73). Con la ayuda directa de Melquíades, el fantasma logró hallar a Macondo y a José Arcadio en los: "abigarrados mapas de la muerte" (p. 73). Con el re-encuentro, José Arcadio se halló de pronto frente a la tragedia aquí también manifiesta en forma de nostalgia: $\because$.. Cuando por fin lo identificó, asombrado de que también envejecieran los muertos, José Arcadio Buendía se sintió sacudido por la nostalgia" (p. 73). Le es así dado el privilegio de experimentar el sufri. miento intenso y con poderes transformadores que sólo los muertos pueden sentir; de pronto se encuentra: ". .llorando con el llantito sin gracia de los viejos, llorando por Prudencio Aguilar, por Melquíades, por los padres de Rebeca... por todos los que podía recordar y entonces estaban solos en la muerte" (p. 73).

No obstante, José Arcadio no ascendió de inmediato al nivel humano, sino que a taíz de los sufrimientos, llegó a la locura; y de aquí en adelante ya no pudo percibir ni distinguir el fluir del tiempo, razón por la cual todos los días fueron lunes en su mente. En estado de demencia, José Arcadio se mantuvo en la inocencia adánica sin alcanzar hasta ahora a conseguir cierta indispensable conciencia de su yo individual: ". . Cuando llegaron Ursula y Amaranta todavía estaba atado de pies y manos al tronco del castaño; empapado de lluvia, y en un estado de inocencia total". (p. 74).

Sin embargo, en su larga o corta permanencia de loco atado por el resto de sus días, José Arcadio pudo llegar a descubrir el amor, a través de un medio prácticamente sobrenatural, pues Prudencio Aguilar y José Arcadio se hicieron amigos entrañables:?

...Hablaban de gallos. Se prometían establecer un criadero de animales magníficos, no tanto por disfrutar de unas victorias que entonces no les harian falta, sino por tener algo con qué distraerse en los tediosos domingos de la muerte. Era Prudencio Aguilar quien lo limpiaba, le daba de comer y le llevaba noticias... (p. 124).

Y ahora que ha podido cumplir con los dos requisitos, José Arcadio pierde la inocencia. La conciencia de su yo, resultante de este proceso de intercambios, está representada una vez más en términos de confrontamiento con la imagen del espejo, que en este caso parece mucho más específico y que aquí se concreta en el artificio de un sueño repetido.

3 Técnica ésta intimamente relacionada con el Realismo mágico del que repetidamente hace uso el autor particularmentè en sus relatos "Blacamán el bueno, vendedor de milagros" (1969) y "Un hombre muy viejo con unas alas enormes" (1968). 
y continuo. Bien sabemos que fue precisamente a través de un sueño como José Arcadio había escogido el sitio en que habría de fundar a Macondo tantos años atrás: "...José Arcadio Buendía soñó esa noche que en aquel lugar se levantaba una ciudad ruidosa con casas de paredes de espejo" (p. 28). Ahora, muchos años después, en su estado de prisionero del castaño, vuelve a soñar con espejos, esta vez concretado en lo que se denomina "sueño de los cuartos infinitos" (p. 124). En dicho sueño el narrador anota que:

.. le gustaba irse de cuarto en cuarto, como en una galeria de es. pejos paralelos, hasta que Prudencio Aguilar le tocaba el hombro. Entonces regresaba de cuarto en cuarto, despertando hacia atrás, recorriendo el camino inverso, y encontraba a Prudencio Aguilar en el cuarto de la realidad. Pero una noche, dos semanas después de que lo llevaron a la cama, Prudencio Aguilar le tocó el hombro en un cuarto intermedio, y êl se quedó alli para siempre, creyendo que era el cuarto real... (p. 124).

José Arcadio ha descubierto su propio yo en los cristales (espejos) de las paredes del cuarto intermedio. Se levantó así al nivel humano y al hacerlo se hizo mortal ya que como el autor anota: "no pudieron despertarlo" (p. 125) de su última sueño.

\section{El caso de José Arcadio, el hijo de Fernanda y Aureliano Segundo}

Para la época de su retorno de Roma a Macondo, José Arcadio todavía no habia perdido la inocencia, es decir, que todavía no había alcanzado su madurez, a pesar de esta larguísima ausencia: ". . . de algún modo imposible de precisar. . seguía siendo un niño otoñal terriblemente triste y solitario" (p. 309), en donde se ve claramente que la experiencia del amor y la tragedia aún estaban por cumplirse. A șu llegada, lo primero que hace es revelar el disgusto enorme que siente por su sobrino bastardo, el último Aureliano. Con plena consciencia de su resentimiento ordena que el muchacho permanezca dentro de la casa y a su disposición:

-Entonces - dijo con voz que tenía algo de navaja de afeitar-, tú eres el bastardo.

-Soy Aureliano Buendía. 
- Vete a tu cuarto —dijo José Arcadio.

Aureliano se fue, y no volvió a salir ni siquiera por curiosidad... (p. 309).

La frialdad del temperamento de José Arcadio se amplía con la descripción física que el narrador da de él. Lo perfila en términos que aluden a la expresión moribunda y neutra de algunas imágenes de cera usadas para representar algunos santos: ". . .mirada vigilante y glacial" (p. 312), aprendida e impuesta por su madre Fernanda quien viviera convencida de que su hijo había nacido para ser Papa y motivo por el cual fuera enviado a Roma:

...El cabello negro, lustrado y liso, partido en el centro del cráneo por una linea recta y exangize, tenía la misma apariencia postiza del pelo de los santos. La sombra de la barba bien destroncada en el rostro de parafina... (p. 309).

Muy al contratio de lo que creyera Fernanda, José Arcadio era un individuo inútil y decadente mientras estuvo fuera de casa y ahora a su retorno: "...dormía hasta después de las once" (p. 311), gastaba largas horas en el cuarto de baño donde: ". . oficiaba un rito que por su parsimonia y duración recordaba el de Remedios, la bella..." (p. 311), y por supuesto que una vez logró descubrir aquel tesoro enterrado de Ursula, por el que Aureliano Segundo iba desquiciando la casa, José Arcadio: "... convirtió la casa en un paraíso decadente" (p. 314) llegando hasta tales excesos que sintió repugnancia de sí mismo y de sus bajezas: "...Enardecido no tanto por los estragos sino por el asco y la lástima que sentía contra sí mismo en el desolado vacío de la saturnal... (p. 315). La debilidad de José Arcadio estaba enraizada en su narcisismo y en aquella enfermiza tendencia a buscar la compañía de los niños pú. beres, de quienes se haría víctima más tarde por motivos de venganza. Entretanto, ahora que no contaba con la ayuda de esos cuatro chiquillos que irían a ahogarlo en la alberca, José Arcadio tiene tiempo para experimentar el hallazgo personal del amor y de tragedia. A raíz del agudizamiento de su enfermedad (el asma) que lo postrara en el lecho con ataques de asfixia, Aureliano se mostró tan compasivo y oportuno que los dos Buendía fueron lentamente trabando una alianza amistosa, sólida. Pues aunque al principio: ". . aquel acercamiento entre dos solitarios de la misma sangre estaba muy lejos de la amistad" (p. 310), pronto se tornó en amor fraternal que empezaba a echar hondas raíces, a la manera 
en que Aureliano habría de verlo en retrospectiva después de su muerte: "..Sólo entonces comprendió [Aureliano] cuánto habia empezado a querer̀lo" (p. 317). Porque José Arcadio, antes envilecido y amargado, ante los ojos de Aureliano, empezó a adquirir verdaderas cualidades humanas:

...Aureliano, por su parte, se sorprendió de que José Arcadio visto de cerca fuera tan distinto de la imagen que se habia formado de él cuando le veía deambular por la casa. Era capaz de reír, de per. mitirse de vaz en cundo una nosallgia del pasado de la casa, y de preocuparse por el ambiente de miseria en que se encontraba el cuarto de Melquíades... (p. 316).

José Arcadio descubrió también la cara de la tragedia. Habría de norir al poco tiempo de haber trabado esta amistad fundada en la com. prensión mutua. Al sentir compasión por Aureliano, apocado y reducido al recinto del 'cuarto de Melquiades, José Arcadio había hecho planes para montarle un negocio aunque: ". . tampoco aquel sueño final había de cumplirse" (p. 317), ya que José Arcadio al poco tiempo habría de ser asesinado por los niños vengativos a quienes había echado de su casa a latigazos. Esta auténtica compasión (amor) por su sobrino que antes calificara de bastarao, le habría de proporcionar el indispensable autodescubrimiento de su condición por la que se asciende al nivel humano. El narrador vierte el retrato de este último descubrimiento que hiciera José Arcadio, valiéndose de la confroniación metafórica que el protagonista efectúa frente al espejo del agua transparente en que muere ahogado:

...Esa tarde, habiéndolo echado de menos en la cocina, buscó [Aureliano] a José Arcadio por toda la casa, y lo encontró flotando en los espejos perfumados de la alberca, enorme y tumefacto, y todavía pensando en Amaranta... (p. 317).

\section{El caso de Ursula Buendía}

También habría de llegar al descubrimiento del amor y la tragedia al final de sus largos años de vida. Fue entonces cuando:

.. en la impenetrable soledad de la decrepitud dispuso de tal clarividencia para examinar hasta los más insignificantes acontecimientos 
de la familia, que por primera vez vio con claridad las verdades que sus ocupaciones de otro tiempo le babian impedido ver... (p. 213).

Para Ursula esta revelación tiene la forma de una crisis del entendi. miento, pues siendo una mujer dedicada a la acción, no había tenido tiempo para la reflexión sobre la conducta de quienes vivían con ella. Ahora entiende los conflictos verdaderos y temperamentales del coronel, de Amaranta y de la misma Rebeca, su hijastra. Y esta súbita revaluación mental sobre sus hijos, trajo consigo el resurgimiento del amor y de la compasión que durante tantos años habían permanecido fosilizados en el subconsciente. Se da cuentâ, por ejemplo, de que su hijo Aureliano había entablado treinta y dos guerras desastrosas por orgullo diabólico y que la tragedia del pobre héroe habia tenido un origen oculto en su innata incapacidad para querer a alguien. Fue entonces cuando: " . . aque. lla desvalorización de la imagen del hijo, le suscitó de un golpe toda la compasión que le estaba debiendo" (p. 214).

Ursula dejó de sentir aquella sensación de amargura y piedad despótica para con Amaranta porque entiende ahora que la crueldad de su hija con Petro Crespi, había sido simplemente la resultante de: ". .un amor sin medidas y una cobardía invencible, y había triunfado finalmente el miedo irracional que Amaranta le tuvo siempre a su propio y atormentado corazón" (p. 214). Inclusive vuelve a sentir amor por Rebeca a quien ella misma había expulsado del hogar hacia ya tanto tiempo:

.. Fue por esa época que Ursula empezó a nombrar a Rebeca, a evocarla con un viejo cariño exaltado por el arrepnitimiento tardio y la admiración repentina, babiendo comprendido que solamente ella, Rebeca, la que nunca se alimentó de su leche sino de la tierra de la tierra y la cal de las paredes, la que no llevó en las venas sangre de sus venas sino la sangre desconocida de los desconocidos cuyos huesos seguían cloqueando en la tumba, Rebeca, la del corazón impaciente, la del vientre desaforado, era la uinica que tuvo la valentía sin frenos que Ursula había deseado para su estirpe... (pp. 214.5).

A través de tales testimonios es apenas conclusivo decir que Ursula también alcanzó el nivel humano que dan las experiencias transformadoras del amor y la tragedia. En la misma visión sintética y espectral 
del último Buendia, el narrador anota que todavía se podía oír la voz de la vieja: "...peleando contra las leyes de la creación para preservar la estirpe" (p. 346), que sintetiza su enorme labor de creadora y conservadora de la estirpe de los hombres y que tanto la emparenta con el símbolo universal de la "madre".

10. El caso "especial" de los otros Buendía

Dentro de la interminable galería de seres que en cien años de vida e historia colectiva pasan bajo los aleros de los Buendía y llevan el apellido, hay algunos que por razones inexplicables para el lector y tal muy explicables para el autor, no viven ninguna de las experiencias trans. formadoras que hemos visto en nueve Buendía, o viven sólo una de las dos pero no ambas, y que son requisito indispensable para alcanzar lo que tantas veces hemos definido como nivel bumano. Entre todos ellos vale mencionar aquí el caso de: José Arcadio (hermano del coronel Aureliano), J. Arcadio Segundo (hermano gemelo de Aureliano Segun. do), Rebeca, Remedios, la bella, Ursula Remedios, Aureliano José (hijo del coronel), etcétera.

Todos tienen en común que desaparecen del marco vital de la novela, o para no volver jamás al salir de Macondo (Ursula Remedios, Santa Sofía de la Piedad y Aureliano, hijo del coronel Aureliano), o quedán. dose voluntariamente para "enterrarse en vida" como decide hacerlo Rebeca (pp. 190-1); muriéndose en la forma más misteriosa de suicidio imaginable como el de José Arcadio, hermano del coronel, con alusiones simbólicas y herméticas: (la pólvora y la sangre, p. 119); o ascendiendo al cielo como Remedios, la bella, por no ser "de este mundo" (p. 172); o muriendo "gemelamente" tal como hubiera nacido y vivido como José Arcadio Segundo, hermano mellizo de Aureliano Segundo (p. 300); o finalmente siendo matado de un disparo absurdo a la entrada de un cine como le sucediera a Aureliano José (p. 136).

Estos personajes de vidas "truncas", silenciados prematuramente por cierto destino implacable, a veces con la ayuda de las manos conscien. temente "descuidadas" del autor, pasan por la obra cumpliendo sus trayetorias meteoríticas, según los postulados de un plan mayor que -con. signado en los arcanos de las profecías de Melquíades- sólo podrá ser alterado después de que se cumplieran al pie de la letra aquellos sucesos cuyo desarrollo requiere cien años de historia.

Tal vez pudiera pensarse que algunos de estos personajes, remo. 
tamente conscientes de la potencialidad del incesto al alcance de sus hechos, hayan optado por "hacerse a un lado" para que pase junto a ellos y sin tocarlos la maldición del "animal mitológico" como sino trágico de la estirpe. Tal parece ser la suetie de José Arcadio, hermano del coronel, casado con su hermanastra Rebeca, agricultor y cazador arraigado a la tierra; o el de Aureliano José, quien parece que "provocara" su misma muerte al desobedecer una orden militar de alto; o de José Arcadio Segundo, quien habiendo escapado milagrosamente del ametra. llamiento masivo que hiciera el ejército sobre la muchedumbre bananera indefensa, vuelve a Macondo saltando del tren de cadáveres (p. 263) para vivir recluido y ensimismado en el cuarto de Melquíades esperando a que su hermano gemelo muera para bajar con él a la tumba que el destino irónicamente les ha equivocado en vida y en muerte. El caso peculiar de Remedios, la bella, sirve para contraponer el concepto de amor y tragedia como exigencias sine qua non se alcanza la condición humana, pues no habiendo podido perder la inocencia, transcurre su vida en un estado semi-angélico que explica por qué no resulta absurdo que un día, extendiendo las sábanas al viento, haya subido al cielo: ". . donde no podían alcanzarla ni los más altos pájaros de la memoria" (p. 205). Sirve de contraste porque su condición adánica es tan inherente a su naturaleza angélica, más allá del bien e intocada por el mal, que difícilmente hubiera podido seguir otro curso su destino: ". . ya que desde el vientre de su madre, estaba a salvo de cualquier contagio" (p. 172).

Marquete University

y

Brown University
GrRmán Darío Carrillo 